Макухина Анастасия Васильевна, соискатель ученой степени, Саратовский государственный аграрный университет имени Н.И. Вавилова. Россия.

410012, г. Саратов, Театральная пл., 1.

Тел.: (8452) 26-27-83.
Ключевъе слова: ресурсный потенциал; методологические подходы; сельскохозяйственные предприятия; агропромышленный комплекс.

\title{
METHODOLOGICAL APPROACHES FOR RESEARCH OF THE RESOURCE POTENTIAL OF AGRICULTURAL ENTERPRISES
}

Makuhina Anastasia Vasilievna, Competitor, Saratov State Agrarian University named after N.I Vavilov. Russia.

Keywords: resource potential; methodological approaches; agricultural enterprises; agro-industrial complex.

The article is devoted to the consideration of methodological approaches to the study of the resource potential of agricultural enterprises. The necessity of detailed consideration of each approach is shown. The necessity of using the synergistic and system approaches is substantiated. The interrelation between all methodological approaches applied at the enterprises is revealed. The methodology of research of approaches used in agricultural enterprises is singled out. The main factors influencing the efficiency of managing the resource potential of enterprises are identified. The mechanism of managing the resource potential of an agricultural enterprise as a single mechanism is considered; its concept and significance are disclosed.

удк 338.436.316.334

\section{ИНФОРМАЦИОННЫЕ ТЕХНОЛОГИИ В РОССИЙСКИХ ОБРАЗОВАТЕЛЬНЫХ УЧРЕЖДЕНИЯХ КАК ВАЖНЕЙШИЙ РЕСУРС РАЗВИТИЯ ОТЕЧЕСТВЕННОЙ ЭКОНОМИКИ}

\author{
САРАНЦЕВ Владимир Николаевич, Московский университет имени С.Ю. Витте \\ ТУПОЛьСКАЯ Татьяна Николаевна, Московский университет имени С.Ю. Витте
}

Рассматриваются актуальные проблемы информатизации российского общества и в частности образовательного процесса как важного условия инновационного развития российской экономики. Анализируется ряд противоречий методологического, педагогического, научного свойства российской системы высшего образования в русле эволюции современного информационного общества. Обосновывается взаимодействие бизнеса, государства и вузовской науки. Эффективное применение информационно-коммуникационных технологий (ИКТ) в образовательном процессе значительно повысит его эффективность.

Введение. Экономические успехи, лидерство в мировой экономике и уровень общественного благосостояния зависят от того, в какой степени экономика страны готова и способна к производству и распространению информации и знаний [15]. По мнению американских ученых, в век информации знания, а не материальные активы или финансовые ресурсы являются ключом к конкурентоспособности [3], т.е. от информационной составляющей бизнеса зависят дальней шее развитие предприятия, эффективное функционирование производственного процесса, место товаров на рынке и многое другое [14]. Знания, квалификация, опыт, навыки человека представляют собой существенный ресурсный фактор, влияющий на развитие экономики в целом, развитие которой в настоящее время переходит на качественно новый уровень, где в достижение высоких социально-экономических результатов решающее значение приобретают именно знания и информационные технологии как инструменты работы с знаниями. Целью данного исследования является анализ выявления проблем информатизации российского общества и в частности системы образования и возможности их разрешения.

Методика исследований. Научные исследования проводились на базетрудов ведущих отечествен- ных и зарубежных ученых как в области взаимосвязи системы высшего образования и инновационной экономики $[1,2,3,8,14,18,19]$, так и эффективного использования информационно-коммукационных технологий в отечественных вузах $[4,5.6,9,12$, 17]. Авторами были использованы методические и справочные материалы, нормативно-правовые акты государственных власти, в том числе федеральные законы и государственные программы [7, 11, 16]. Основными методами исследования были диалектический; анализа и синтеза; экономико-статистический и проблемно-хронологический.

Результаты исследований. Как было отмечено выше, современная экономика - это экономика знаний, основанная на потоке инноваций. На постоянном технологическом совершенствовании и производстве высокотехнологичной продукции с высокой добавленной стоимостью. Ключевым продуктом экспорта на глобальные рынки становятся не товары, а сами технологии. Именно такой тип экономики обеспечивает мировое экономическое превосходство страны Повышение инновационной активности и переход на инновационный тип развития зафиксирован в Стратегии инновационного развития Российской Федерации на период до 2020 года, конечная цель которой - обеспечение 
доминирующей роли знаний в темпах экономического роста [16]. По мнению отечественных экономистов, проблема повышения инновационной активности характерна для всей российской экономики. Примером данного тезиса может служить тот факт, что большинство отечественных продовольственных цепочек характеризуются отсутствием или рудиментарностью начальных стадий, отвечающих за создание и внедрение инноваций, и таким образом, управляются извне, что подрывает продовольственную независимость страны [2].

Решение данной проблемы возможно лишь на основе взаимодействия государства, бизнеса и науки (университетов) [19]. Первостепенную роль в этой триаде, по нашему мнению, должны играть вузы и научно-исследовательские институты, так как прежде чем поддерживать и внедрять инновационный продукт, его необходимо создать. При этом мы не склонны упрощать данный процесс, учитывая участие в нем помимо университетов, центров исследования и разработок, бизнес-инкубаторов, центров трансфера технологий и кластерного развития и целого ряда подобных институтов, как правило, финансируемых государством.

Уровень инновационной активности субъектов экономики как и качество жизни граждан определяется в значительной мере распространение информационных технологий и доступом к ним. Согласно Государственной программе РФ «Информационное общество (2011-2020 гг.), информатизация образования определяется как процесс эффективного использования информационно-коммуникационных и электронных образовательных ресурсов в сфере образования и управленческой практике, а также обеспечения доступности качественного образования, соответствующего требованиям инновационного социально ориентированного развития Российской Федерации, независимо от места жительства, социального и имущественного положения [7].

Проводником новых знаний на протяжении столетий являлись университеты, ведущие свое начало в Европе с XII в. Однако в традиционной российской информационно-знаниевой среде студенты получают знания, которые успевают устареть до того, как появятся в аудитории и библиотеках. По оценкам экспертов, актуальность новых знаний сохраняется в течение 3-5 лет с момента их получения для создания инноваций. Подтверждением тому служат окружающие нас в повседневной жизни предметы: мобильные устройства, автомобили, продукты питания, в производстве которых используется множество новых достижений науки [17].

Новые информационно-коммуникационные технологии ведут к зарождению нового мира, где практически отсутствуют барьеры на создание, обмен и распространение знаний. В основном это связано с развитием Интернета и новыми технологиями, такими как web 2.0, которые минимизируют количество звеньев на пути знаний от их создания до их воплощения в инновации. На основе совре- менных ИКТ создается единое информационное пространство, включающее базы данных деловой и научной информации, сообщества профессионалов, потребителей, где знания свободно циркулируют, невзирая на авторитеты от науки и образования.

Обеспечение качества и доступности образования в соответствии с требованиями Федерального закона «Об образовании в Российской Федерации» [11] в перспективе всё в большей степени будет определяться развитием ИТ-инфраструктуры, применением электронного обучения и дистанционных образовательных технологий, что особенно важно для непрерывной многоуровневой университетской подготовки школьников, бакалавров, магистров и аспирантов.

Стоит отметить, что дистанционное обучение в России набирает обороты, при чем не только в высших учебных заведениях, но и в школах. При этом дистанционное обучение может быть не только на постоянной основе, но и временное, вызванное определенными условиями. Так, к примеру, в феврале 2018 г. в г. Череповце в школе № 24 один из классов был переведен на дистанционное обучение, поскольку двое учеников класса заболели внебольничной пневмонией, девять - ОРВИ. Остальные девять классов учатся дистанционно из-за высокой заболеваемости ОРВИ [10]. Не менее значимо дистанционное обучение и для сельских малокомплектных школ. Речь в данном случае идет не только о том, что учащиеся младших и средних классов не будут «вырываться» из привычной домашней обстановки, но и возможности профильного обучения в старших классах, в том числе в сельской местности, в качестве одного из направлений модернизации [4].

В соответствии с законом и требованиями нового поколения федеральных государственных образовательных стандартов определены такие важные понятия, как «электронное обучение», «дистанционные образовательные технологии», «электронная информационно-образовательная среда», «электронно-библиотечная система (электронная библиотека)», «электронный образовательный ресурс» и др. Благодаря этому российские образовательные учреждения получили правовую основу для перехода от традиционного обучения в ИТ-насыщенной среде к электронному обучению, предусматривающему не только преобразование технологий и процесса обучения, но и разработку новых подходов к управлению университетом, процессами закупки, разработки и применения электронных ресурсов, управлением интеллектуальной собственностью.

Исследователь Б.М. Познееев пишет, что современные тенденции в области формирования информационного общества и развития трансграничного образования обусловливают необходимость ускоренной адаптации российской системы образования к общепризнанным на мировом уровне правилам и нормам в области обеспечения качества и стандартизации. С точки зрения обеспечения конкурентоспособности и гарантий качества особое значение имеет разработка на- 
циональных стандартов, гармонизированных с международными стандартами и условиями международных соглашений и договоров [13].

Это возможно при условии активной работы представителей Российской Федерации в Международной организации по стандартизации, Международной электротехнической комиссии и различных международных объединениях. Международная организация по стандартизации и Международная электротехническая комиссия совместно разрабатывают международные стандарты в области информационных технологий.

Вопросы информатизации сферы образовании очень обширны, что не дает возможность их рассмотрения в настоящей статье в полном объеме. Несмотря на это, можно указать, что процесс информатизации области образования в российском государстве развивается по следующим ключевым направлениям:

оснащение учреждений образования современными техническими средствами для применения информационно-коммуникационных технологий и их использование в качестве новейшего педагогического инструмента, который позволяет в значительной степени повысить результативность образовательного процесса;

применение современных средств информационно-коммуникационных технологий и баз данных для поддержания процесса образования, обеспечения удаленного доступа педагогов и студентов, учащихся к учебной, методической и научной информации как своего государства, так и прочих государств мирового сообщества;

развитие и наиболее обширное распространение дистанционных образовательных технологий - новейшего метода осуществления образовательных и самообразовательных процессов;

пересмотр и радикальная смена содержания образования на всех уровнях, которые обусловлены стремительной эволюцией процесса информатизации в обществе.

Введение и развитие в России дистанционных образовательных технологий активно реализуется лишь в последнее десятилетие. Появление новейших технологий образования стало насущной надобностью, считает В.А. Красильникова [9]. На сегодняшний день процесс информатизации в России достиг такого уровня, что под его воздействием изменяется социальная система и социальная структура: создаются условия для интенсивного, целенаправленного применения информационных технологий в общественной жизни, реализуется целая череда мероприятий по информатизации социальной инфраструктуры в рамках федеральных и областных проектов, приоритетных государственных программ, информационного законодательства.

Вместе с тем, как справедливо отмечают А.С. Петрова, Ю.В. Афанасьева, Н.Н. Левкина, данный процесс в Российской Федерации сейчас во многом имеет неконтролируемый характер, вследствие чего государством упускается возмож- ность его использования в целях уменьшения степени информационного неравенства, увеличения гражданской активности, духовного и культурного возрождения общества, достижения общественной устойчивости [12]. Аналогичной позиции придерживается также С.Е. Гасумова [5].

Активное использование информационных технологий повышает эффективность процесса обучения, поскольку образовательный процесс становится более гибким, интенсивным, обеспечивает индивидуальный подход; обучающиеся могут более продуктивно заниматься самоподготовкой к учебным занятиям, усвоением изученного и получением дополнительного учебного материала, закреплением необходимых умений и навыков; преподаватели и обучающиеся могут более эффективно заниматься исследовательской деятельностью; преподаватели и учебные заведения получают возможность совершенствования процесса преподавания, обмена передовым педагогическим опытом [6].

В настоящее время момент процедура внедрения и применения информационных технологий в образовании в России существенно тормозится и реализуется неравномерно из-за ряда проблем, исследование и классификация которых весьма важны с точки зрения необходимости их результативного решения. К основным трудностям процесса информатизации образовательной среды можно отнести:

повышение общественного неравенства, так как приобретение дорогой техники доступно не всем;

угрозу уменьшения значимости устной и письменной речи, так как в новейших разработках в основном доминирует звук и изображение;

бездействие в процессе освоения данных, так как у создателей программ имеется желание сделать свой материал обычным и не требующим особых усилий;

угрозу снижения уровня социализации личности, то есть внезапное уменьшение времени присутствия среди других людей и общения с ними, посещения социальных и культурных мероприятий, театров, музеев.

Важными проблемами введения информационно-коммуникационных технологий в образовательную сферу, ограничивающим, по мнению ряда исследователей, модернизацию отечественного образования являются:

неподготовленность преподавателей к информатизации образования: как психологическая, так и в силу недостаточного владения информационными технологиями;

недостаток методических материалов по применению информационно-коммуникационных технологий в образовательном процессе;

низкий уровень обеспеченности образовательных учреждений современным оборудованием, в том числе и мультимедийным;

недостаток специалистов, одинаково владеющих технологиями обучения, компьютерными и мультимедийными технологиями на уровне, позволяющем считаться лидером в коллективе; специалистов, спо- 
собных привлечь коллектив к внедрению информационных технологий в образовательную сферу.

Необходимо отметить, что все более активное использование информационных технологий в образовательном процессе сопряжено с рядом негативных последствий, в том числе:

дефицит «живого» общения и, как следствие, возможные трудности в последующей социализации и профессиональной деятельности: проблемы формирования навыков формулирования и выражения своих мыслей, ведения диалога и др.;

наличие в сети Интернет огромного массива готовых работ (докладов, рефератов, курсовых и контрольных работ, дипломов, проектов, решебников и т.п.) снижает эффективность обучения и воспитания обучающихся;

избыток информации, зачастую представленной бессистемно, включающей недостоверные и устаревшие сведения, может отвлекать внимание от учебы, снизить мотивацию и интерес обучающихся, вызвать информационную перегрузку и в результате проблемы со здоровьем, прежде всего, психическим.

Вместе с тем, становится очевидным то обстоятельство, что формирование системы образования будет осуществляться неразрывно с информатизацией всего общества. Реальность настоящего времени такова, что регулярно увеличивается необходимость в использовании новых достижений в сфере информационных технологий и в образовательной сфере. Именно поэтому следует уделять особое внимание перспективным тенденциям и формам обучения с применением информационных технологий.

Например, все большую популярность приобретают концепции мобильного обучения и мобильного тестирования, к примеру, в виде SMSтестирования. Увеличение количества карманных персональных компьютеров, смартфонов, планшетов и других беспроводных устройств справедливо приводит к необходимости использования мобильной связи в обучении. Продолжают совершенствоваться такие новейшие виды информационных технологий, как теле- и видеоконференции.

Телеконференция дает возможность педагогу и обучающимся, находящимся на расстоянии друг от друга, осуществлять учебный процесс, близкий к традиционному, организовывать групповую деятельность обучающихся, пребывающих в разных населенных пунктах, использовать в учебном процессе деловые игры, мозговой штурм и др. Все перечисленное становится возможным вследствие реализации виртуального класса на базе телеконференций, представляющего собой один из видов дистанционного обучения.

По мнению ряда специалистов, в том числе А.С. Петрова, Ю.В. Афанасьева, и Н.Н. Левкина, дистанционное обучение является более продвинутой образовательной технологией по сравнению с заочным обучением.

Сохраняя основные плюсы заочного обучения - способность обучаться на дому, в комфортное для себя время и независимо от места проживания, дистанционное обучение имеет огромную гибкость и интерактивность. В то время, как заочные курсы работают согласно расписанию, дистанционный курс может начаться в любой момент по желанию учащегося, сроки обучения не установлены конкретно, и обучающийся сам выбирает для себя подходящий темп работы. Дистанционный педагог постоянно доступен по электронной почте и готов дать ответы на всевозможные появляющиеся у учащегося вопросы.

Вместе с тем, активное применение сети Интернет и информационных технологий в ходе учебного процесса требует формирования новых электронных учебных материалов, перестройки содержания и организационных форм учебной деятельности и переподготовки педагогических кадров.

Таким образом, в современных условиях информационные технологии выступают как технические средства разрешения основных вопросов в период развития новых общественно-экономических условий жизни общества. Несмотря на постоянное развитие форм и методов информатизации образования, данный процесс сопряжен с целым рядом проблем, в решении которых необходимо активное участие государства и всех участников образовательного процесса.

Заключение. Совокупность ИКТ в обществе переходит в новое качество коммуникации между потребителями и товаропроизводителями, гражданами и властью, учениками и образовательными учреждениями. Впервые у представителей бизнеса, органов государственного управления, университетов и ряда других субъектов появляются технологии моментальной обратной связи, сигнализирующих об изменениях во внешней среде. Бесспорно, применение информационно-коммуникационных технологий в экономике позволит компаниям достигнуть новых экономических эффектов за счет адаптации к постоянно изменяющейся бизнес-среде, ускорит процесс создания мобильных офисов, непрерывной связи с партнерами и потребителями, т.е. к созданию новой инновационной экономики.

\section{СПИСОК ЛИТЕРАТУРЫ}

1. Александрова Л.А., Павлова Е.Н. Интеграция вузов и сельскохозяйственных предприятий в рамках инновационной квадроспирали // Аграрный научный журнал. - 2017. - № 4. - С. 75-80.

2. Александрова Л.А., Павлова Е.Н.Инновационная спираль в сельском хозяйстве Саратовской области: барьеры, стимулы и сценарий формирования // Аграрный научный журнал. - 2018. - № 3. - С. 58-62.

3. Армстронг М. Практика управления человеческими ресурсами. - М.- СПб., 2009. - 846 с.

4. Былина С.Г. Проблемы информатизации образования в сельских школах // Аграрный научный журнал. -2016. - № 1. - С. 65-69.

5. Гасумова С.Е. Информационные технологии в социальной сфере: учеб. пособие. - М., 2015. - 350 с.

6. Зуев Н.А., Левкина Н.Н. Информационные технологии в образовании: возможности и негативные последствия // Общество в эпоху перемен: формирование новых социально-экономических отношений: материалы V Междунар. науч.-практ. конф. - Саратов, 2014. - С. 92-93.

7. Информационное общество (2011-2020 годы): Государственная программа Российской Федерации; 
утв. Распоряжением Правительства РФ от 20 октября 2010 г. № 163-p. - Режим доступа: http://minsvyaz.ru/ $\mathrm{ru} /$ activity/progrrams/1/.

8. Кехян М.Г., Шуваев М.А. Роль образовательного кластера в формировании инновационной экономики региона // Аграрный научный журнал. -2015. № 7. - С. $81-85$.

9. Красильникова В.А. Информационные и коммуникационные технологии в образовании: учеб. пособие. - М., 2016. - 231 с.

10. Макарова Л. В Череповце из-за ОРВИ десять классов в шести школах перевели на дистанционное обучение // Голос Череповца. - 2018. - № 10 (2). - С. 4 .

11. Об образовании в Российской Федерации: [Федер. закон принят Гос. Думой 29 дек. 2012 г., по сост.: 29 дек. 2017 г.]. - Режим доступа: http://www.pravo.gov.ru.

12. Петрова А.С., Афанасъева Ю.В., Левкина Н.Н. Информатизация образования: проблемы и перспективы // Интерактивная наука. - 2017. - № 11 (21). - С. 39-42.

13. Позднеев Б.М. О создании электронной информационно-образовательной среды на основе стандартов e-learning // Современные информационные технологии и ИТ-образование. - 2015 - Т. 1 (№ 11). - С. 21-24.

14. Ромашкин T.B. Информационное обеспечение бизнеса в современных условиях // Аграрный научный журнал. - 2017. - № 3. - С. 95-100.

15. Соколова О.Ю. Особенности развития национальной системы образования в условиях членства России в ВТО // Вестник Саратовского госагроуниверситета им. Н.И. Вавилова. - 2014. - № 4. - С. 89-93.
16. Стратегия инновационного развития Российской Федерации на период до 2020 года: утв. Распоряжением Правительства РФ от 8 декабря 2011 г. № 2227-p. - Режим доступа: http://www.garant.ru/ products/ipo/prime/doc/70006124/\#ixzz4x47B1LYz.

17. Тихомиров В.П., Днепровская Н.В. Смартобразование как основная парадигма развития информационного общества // Современные информационные технологии и ИТ-образование. - 2015. T. 1 (№ 11). - C. 9-13.

18. Чесбро Г. Открытые инновации. Создание прибыльных технологий; пер. с англ. - М.: Поколение, 2007. - 336 c.

19. Etzkowitz H., Leydesdorff L. The dynamics of innovation: from National Systems and «Mode 2» to a Triple Helix of university-industry-government relations // Research Policy, 2000, 29, 109-123.

Саранцев Владимир Николаевич, канд. экон. наук, доцент кафедры «Экономика городского хозяйства и сферы обслуживания», Московский университет имени С.Ю. Витте. Россия.

Тупольская Татьяна Николаевна, магистрант факультета экономики и финансов, Московский университет имени С.Ю. Витте. Россия.

127550, г. Москва, 2-й Кожуховский пр., д. 2, стр. 1.

Тел.: 89271383429; e-mail:kvnraritet@mail.ru.

Ключевые слова: экономика; инновации; бизнес; университетское образование, информатизация, информационно-коммуникационные технологии.

\title{
INFORMATION TECHNOLOGIES IN RUSSIAN EDUCATIONAL INSTITUTIONS AS THE MOST IMPORTANT RESOURCE FOR THE DEVELOPMENT OF THE DOMESTIC ECONOMY
}

Sarantsev Vladimir Nikolaevich, Candidate of Economic Sciences, Associate Professor of the chair "Economics of Municipal Services and Services Sector", Moscow University named after S.Yu. Vitte. Russia.

Tupolskaya Tatyana Nikolaevna, Magistrandt, Moscow University named after S.Yu. Vitte. Russia.

Keywords: education; innovations; business; university education; informatization; information technology.
The actual problems of informatization of Russian society and in particular the educational process as an important condition for innovative development of the Russian economy are considered. A number of contradictions of the methodological, pedagogical, scientific quality of the Russian system of higher education are analyzed in the mainstream of the evolution of the modern information society. The interaction between business, government and university science is grounded. Effective use of information and communication technologies (ICT) in the educational process will significantly increase its effectiveness.

удК $334.72+332.021 .8$

\section{СОВРЕМЕННЫЕ ТЕНДЕНЦИИ РАЗВИТИЯ ХОЗЯЙСТВЕННЫХ ИНСТИТУТОВ АГРОПРОДОВОЛЬСТВЕННОГО КОМПЛЕКСА РОсСии}

\author{
ШАБАНОВ Виктор Леннарович, Институт аграрных проблем РАН
}

На основе показателей землепользования и производства сельскохозяйственной продукции проанализирована динамика развития сельскохозяйственных организаций, крестьянских (фермерских) и лииных подсобных хозяйств. Показаны тенденции концентрации земли и замещения сельскохозяйственными организациями личных подсобных хозяйств в сельскохозяйственном производстве. Проанализированы изменения российского законодательства, посвященного сельскому развитию.

Введение. В результате реорганизации колхозов и совхозов, проведения земельной реформы, образования крестьянских (фермерских) хозяйств был сделан первый шаг на пути создания многоукладной аграрной экономики. Системные реформы 1990-х гг. создали принципиально новые социально-экономические условия, оказав- шие существенное влияние на все сферы сельской жизни [3]. Юридической базой реформ стали Законы РФ «О земельной реформе» (№ 374-I от 23.11.1990) и «О крестьянском (фермерском) хозяйстве» (№ 348-I от 22.11.1990), Постановление Правительства РФ «О порядке реорганизации колхозов и совхозов» (№ 86 от 29.12.1991). 